\title{
Socio-economic Factors Influencing Profitability of Rice Seed Production in Selected Areas of Bangladesh
}

\author{
M. Z. Hoque* and M. E. Haque \\ Department of Agricultural Extension and Rural Development, Bangabandhu Sheikh Mujibur Rahman \\ Agricultural University, Salna, Gazipur-1706, Bangladesh \\ *Corresponding author and Email: zia.bsmrau@gmail.com
}

Received: 12 February 2014

Accepted: 14 June 2014

\begin{abstract}
Seed is the foundation of agriculture for enhancing crop production. The economic benefits from the improved quality seed production help scaling up the livelihood standard as well as nutritional status of the common people. The study was carried out in three districts namely Jamalpur, Gazipur and Manikganj to identify the socio-economic dimensions of the government seed production project beneficiaries persuading profitability of rice seed production. Data were collected through intensive survey of randomly selected 211 sample respondents using pre-tested interview schedule. To examine the profitability of rice seed production, the gross margin and cost benefit analysis were carried out. Co-efficient of correlation and multiple stepwise regressions were employed to find out the determinants of profitability in rice seed production. Rice seed production was not found to be so profitable as investment in rice seed cultivation can produce average BCR of only up to 1.44 , where highest BCR was found in Jamalpur (1.58) compared to Manikganj (1.48) and Gazipur (1.26). The results revealed that socio-economic factors have a profound influence on profitability of rice seed production as these factors combined explained 54.9 percent variation. Farm size, contact with information sources, knowledge on quality rice production and age of the respondents were identified as significant contributors in profitability of rice seed production, whereas contact with information sources was the single most influential factor (24.6\%). Therefore, steps may be taken so that the seedgrowers could directly be linked with more information sources dealing with seed production and marketing through the government initiatives to boost up the production as well as to ensure appropriate price of the farmers' home grown seed.
\end{abstract}

Keywords: Rice seed production, gross margin, cost-benefit ratio, determinants

\section{Introduction}

Among the cereal crops grown in Bangladesh, rice occupies about 79.4 per cent of the total cultivable land and dominates the cropping pattern throughout the country. Rice based cropping pattern dominates throughout the country since almost 90 percent people are rice eaters. Rice contributes to over 63 percent of the caloric intake for urban consumers and over 71 percent for the rural population. The percentages are much higher among the poor (Anonymous, 2003). Increasing supply of quality seed is an appropriate strategy for ensuring food security. Use of quality seed can increase productivity of almost all the crops. Seed plays a two-way role, production is affected due to inferior quality of seed and economic loss is incurred due to misuse 
of other inputs with inferior seed. Availability of quality seed is one of the major constraints in increasing the productivity of agricultural crops. At present only 5, 18 and $13 \%$ of rice, wheat and jute seeds respectively are supplied from recognized seed companies and the rest of the seeds are available from farmers' sources (Huda, 2001).

Cost effectiveness of rice seed production is most important in rice cultivation by which a farmer feels interested to produce more rice seed for his economic development. Profitability of seed production means return getting from every taka of investment in rice seed production. If a farmer gets more benefit from rice crop for seed production than normal rice production then the farmer is habitually very much interested to cultivate his land for seed production. From the economic point of view, if the farmers get minimum 1:1.50 taka for every taka of investment then it seems to be cost effective and the benefit is economically acceptable (Islam, 2010). Like the basic inputs viz. seed, fertilizers, pesticides, irrigation and appropriate management, apart from socio-economic factors, may also influence the effectiveness of rice seed production at farmer's level. Socio-economic status is an economic and at the same time a social measure of a person's position in the society relative to others, based on income, education, and occupation. The socio-economic factors usually influence farmers' decisions as to which crop/variety is to be grown, which enterprise is to be run and so on.

There are some socio-economic factors, having influences even on the particular crop production practice are to be followed, which might have significant impact on crop yield and productivity. Farm size, farmers` education level, technical knowledge of the farmers, training and farming experience etc. may have positive relationship with crop yield. The factors like farmers low income, lack of personal and interpersonal communication skill, less exposure to media etc. might have negative relationship with crop yield and productivity. Different socio- economic factors like education level, farming experience, farm size, linking with GO/NGOs, annual income etc. play a significant role in the adoption process of modern agricultural technologies among the farmers. The farmers who have higher socio-economic status could easily adopt the modern technologies or could take any risk of the new technologies for scaling up their agricultural production. Moreover, the success of modern agriculture is dependent on the farmers' knowledge and experience along with available inputs. In view of the above, this study was conducted to achieve the following objectives:

i. To describe the socio-economic characteristics of the selected rice seed growers;

ii. To measure the profitability of rice seed production at farmers level in selected areas of Bangladesh; and

iii. To explore the relationships between profitability of rice seed and rice seed growers' selected characteristics;

\section{Methodology}

\subsection{Study area}

The study was conducted in purposively selected three districts namely Jamalpur, Gazipur and Manikgonj considering highly concentrated rice growing areas.

\subsection{Population and sample of the study}

Multistage proportionate random sampling technique was used in this study. At first, three districts were selected purposively. Then three upazilas of the three districts (one from each district) were selected randomly. After that, six blocks (two from each upazila) were selected on a random basis. Finally, twelve villages (two from each block) were also selected randomly. From the selected villages, a list of 467 beneficiaries of government seed production project was done, which constituted the active population for the study. Out of 467 farmers, 211 farmers were selected as sample of the study by adopting the following formula (Kothari, 1990): 


$$
n=\frac{z^{2} \cdot p \cdot q \cdot N}{e^{2}(N-1)+z^{2} \cdot p \cdot q}
$$

Where,

$\mathrm{n}$ = sample size,

$\mathrm{z}=$ the value of the standard variety at a given confidence level and to be worked out from table showing area under normal curve. In the present study it was considered standard normal deviate at $95 \%$ confidence level = 1.96.

$\mathrm{p}=$ sample proportion, which may be based on personal judgment, experience or may be result of a plot study. In absence of such estimation one method may be taken the value of $p=0.50$ in which case 'n' will be the maximum and the sample will yield at least the desired precision. In the present study value of $\mathrm{p}$ was estimated as 0.50 .

$\mathrm{q}=1-\mathrm{p}$ (in the present study $\mathrm{q}=1-0.50=0.50$ )

$\mathrm{e}=$ Acceptable margin of error (the precision) usually considered 0.05 .

$\mathrm{N}=$ Size of population

Sample size at $95 \%$ confidence level and at 5\% margin of error $=$

$\{(1.96 \times 1.96) \times 0.50 \times 0.5 \times 467\}$

$[\{(0.05 \times 0.05) \times(467-1)\}+\{(1.96 \times 1.96) \times 0.5 \times 0.5\}]$

$=\frac{448.51}{2.13}$

$=211$

\subsection{Measurement of variables}

The independent variables of the study were the selected socio-economic characteristics viz. age, education, family size, farm size, farming experience, organizational participation, training experience, contact with information sources and annual income of the rice seed growers whereas, profitability of rice seed production was considered as dependent variable. The independent variable was measured following standard procedure. Profitability of rice seed production was measured by computing BCR (Benefit Cost Ratio) following Chowdhury et al. (2012) as:
Where,

$$
\begin{aligned}
& \text { BCR }=\text { Gross return } \\
& \text { Total input cost } \\
& \text { Total input cost }
\end{aligned}
$$

Per hectare total cultivation cost of rice was estimated as the sum total of cultural and intercultural operation cost, different input cost, post harvest operation and related costs.

\section{Gross return}

Gross return was defined by sum of the market price of paddy and the price of straw per hectare area in the year (2012) under study:

Where,

Gross return $=$ Total market price of paddy + Price of straw.

\subsection{Data collection and analysis}

Data were collected through pretested interview schedule during March to September 2012 through intensive survey by the researcher. After collection of data, all the information contained in the interview schedule was edited. All the collected data were then checked and cross checked, compiled, coded and entered into the computer for analysis and interpretation using Microsoft Excel and Statistical Package for the Social Sciences (SPSS). Qualitative data were converted into quantitative form. Statistics like means, percentages, standard deviation and frequencies were used to describe selected characteristics of the respondents. Multiple regression and stepwise regression were computed to find out the determinants of profitability of rice seed production. Economic analyses were applied to determine BCR, gross margin and marginal benefit cost ratio of rice seed production.

\section{Results and Discussion}

\subsection{Socio-economic profile of the respondents}

Table 1 reveals that the highest proportion of the respondents were old aged (47.9\%) compared to young $(21.3 \%)$ and middle aged $(30.8 \%)$. Nearly two-third $(65.4 \%)$ of the respondents was found to be literate as per national literacy rate ranging from primary to above secondary level. An 
overwhelming majority of the respondents belonged to small $(35.1 \%)$ and medium $(38.9 \%)$ sized family. Except a few, almost all the respondents had medium to long time farming and seed production experience $(91.4 \%)$. With regard to farm size, 88.2 percent of the respondents of the study area were medium and large farmers and more than four-fifths $(80.5 \%)$ had medium to high contact with information sources. In respect of knowledge and training, almost all the farmers had good knowledge in agriculture since they had good training on agriculture. More than half $(56.8 \%)$ of the respondents had moderate to highly favourable attitude and 85.8 percent had medium to high income. It appeared that the selected characteristics could have influenced sufficiently towards profitability of rice seed production.

Table 1. Distribution of the respondents according to their socio-economic characteristics

\begin{tabular}{|c|c|c|c|c|c|}
\hline Character & Unit & Categories & $\%$ & Mean & SD \\
\hline \multirow{3}{*}{ Age } & \multirow{3}{*}{ Actual year } & Young age(21- 35 years) & 21.3 & \multirow{3}{*}{46.20} & \multirow{3}{*}{10.15} \\
\hline & & Middle age(36 -50 years) & 30.8 & & \\
\hline & & Old age(above 50 years ) & 47.9 & & \\
\hline \multirow{5}{*}{ Education } & \multirow{5}{*}{$\begin{array}{l}\text { Year of } \\
\text { schooling }\end{array}$} & Can sign only & 34.6 & \multirow{5}{*}{4.11} & \multirow{5}{*}{3.69} \\
\hline & & Primary (1-5) & 32.2 & & \\
\hline & & Secondary (6-10) & 29.9 & & \\
\hline & & Higher secondary (11 to 12 ) & 1.9 & & \\
\hline & & Above higher secondary (above 12) & 1.4 & & \\
\hline \multirow{3}{*}{ Family size } & \multirow{3}{*}{ Number } & Small family (1-4) & 35.1 & \multirow{3}{*}{5.70} & \multirow{3}{*}{2.38} \\
\hline & & Medium family (5-6) & 38.9 & & \\
\hline & & Large Family (> 6) & 27.0 & & \\
\hline \multirow{3}{*}{$\begin{array}{l}\text { Farming } \\
\text { experience }\end{array}$} & \multirow{3}{*}{ No. of years } & Low (1-10 years) & 9.0 & \multirow{3}{*}{24.02} & \multirow{3}{*}{9.989} \\
\hline & & Medium (11-20 years ) & 33.6 & & \\
\hline & & High (>20 years) & 57.8 & & \\
\hline \multirow{3}{*}{ Farm size } & \multirow{3}{*}{ Hectare } & Small (up to 1.00 ha) & 12.3 & \multirow{3}{*}{2.71} & \multirow{3}{*}{1.77} \\
\hline & & Medium (1.01 to3.0ha) & 56.4 & & \\
\hline & & Large (>3.0 ha) & 31.8 & & \\
\hline \multirow{3}{*}{$\begin{array}{l}\text { Contact with } \\
\text { sources of } \\
\text { information }\end{array}$} & \multirow{3}{*}{ Score } & Low contact (1-13) & 19.4 & \multirow{3}{*}{19.16} & \multirow{3}{*}{6.23} \\
\hline & & Medium contact (14-25) & 63.0 & & \\
\hline & & High contact $(>25)$ & 17.5 & & \\
\hline \multirow{3}{*}{ Knowledge } & \multirow{3}{*}{ Score } & Low knowledge (up to 8) & 1.4 & \multirow{3}{*}{12.43} & \multirow{3}{*}{5.20} \\
\hline & & Medium knowledge (9-14) & 67.8 & & \\
\hline & & High knowledge(> 14) & 30.8 & & \\
\hline \multirow{4}{*}{ Attitude } & & Unfavorable attitude (up to 70) & 43.6 & & \\
\hline & & Moderately favorable attitude (71- & & & \\
\hline & Score & 101) & 46.4 & 72.80 & 8.58 \\
\hline & & $\begin{array}{l}\text { Highly favorable attitude (102 and } \\
\text { Above) }\end{array}$ & 10.4 & & \\
\hline & & No training (0 days) & 1.4 & & \\
\hline Troini & & Poor training( $1-3$ days) & 93.8 & & \\
\hline Trainıng & No. of days & Medium training (4-5 days) & 0.5 & 1.83 & 2.66 \\
\hline & & High training (above 5 days) & 4.3 & & \\
\hline & & Low income (up to 100) & 14.2 & & \\
\hline 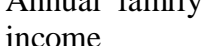 & Tk/vear & Medium income (between 101-200) & 47.4 & 203.29 & 1262.49 \\
\hline & & High income (above 200) & 38.4 & & \\
\hline
\end{tabular}


Table 2. Cost and return (Tk/ha) of rice seed production in different study areas

\begin{tabular}{lllll}
\hline Cost items & \multicolumn{4}{c}{ Study Area } \\
\cline { 2 - 5 } & Jamalpur & Gazipur & Manikganj & Average \\
\hline Land preparation & 8326.37 & 12135.60 & 9277.81 & 9913.26 \\
Cowdung \& manuring & 1838.96 & 3621.46 & 2082.73 & 2514.39 \\
Fertilizer & 11304.20 & 15435.03 & 14444.56 & 13727.93 \\
Seed & 2271.21 & 5038.55 & 1459.42 & 2923.06 \\
Transplanting & 8433.82 & 11710.02 & 10331.52 & 10158.45 \\
Mulching \& intercultural operation & 9854.56 & 13521.52 & 11659.14 & 11678.41 \\
Irrigation & 17568.37 & 19034.31 & 13334.05 & 16645.58 \\
Top dressing & 980.12 & 2810.61 & 2068.63 & 1953.12 \\
Harvesting \& post harvest \& storage & 2455.43 & 2564.35 & 2026.17 & 2348.65 \\
Land rental & 18096.95 & 20824.57 & 18308.88 & 19076.80 \\
Revenue & 25458.29 & 29005.21 & 25702.82 & 26722.11 \\
\hline Total cost of cultivation ( on full & 106588.28 & 135701.26 & 110695.72 & 117661.75 \\
cost basis) & & & & \\
Gross return (total price of the & 168384.84 & 170504.10 & 163886.97 & 167591.97 \\
produce i.e. crop yield + straw) & 61796.56 & 34802.84 & 53191.25 & 49930.22 \\
Net return & 1.58 & 1.26 & 1.48 & 1.44 \\
BCR & & & & \\
\hline
\end{tabular}

\subsection{Production cost and profitability of rice seed production}

The cost of crop production and its return mainly depends on the rate of inputs used (seed, fertilizers, pesticides etc), land/soil type, number of irrigation needed, number of labor and their wage rate, management practices, marketing facilities of the crop products etc. As all these factors differed from one location to another across the study areas, the production cost and hence, the economic return for rice seed as assessed through the present study presumably varied widely. The production package and profitability analysis for Boro rice in Jamalpur, Gazipur and Manikganj sites are presented in Table 2.

The highest average cost of production was observed in Gazipur (Tk.135701.26/ha) compared to Manikganj (Tk.110695.72/ha) and Jamalpur (Tk.106588.28/ha). Besides, the highest average gross return was also recorded in Gazipur (Tk. 170504.10/ha) followed by Jamalpur (Tk. 168384.84/ha) and Manikganj (Tk. 163886.97/ha). The highest average benefit cost ratio (BCR) was found in Jamalpur (1.58) followed by Manikganj (1.48) and Gazipur (1.26). It was observed that the average cost of cultivation on full cost basis was Tk. $117661.75 /$ ha. Besides, the average gross return was Tk. 167591.97/ha. The average benefit cost ratio (total cost basis) was 1.44 . It can be cocluded that Boro rice cultivation for seed purpose is not that much profitable. Ali et al. (2008) reported that BCR of Boro rice was 1.53. Islam (2010) reported that total variable costs, gross return and BCR for Boro rice were Tk. 43,549/ha, 92,294/ha and 1.66, respectively. Rahman (2011) reported that average net return from BRRIdhan28, BRRIdhan29 and hybrid rice of control respondents were Tk. 47426.38, 58470.12 and 46085.21 per hectare, respectively. On the other hand, treatment respondents obtained Tk. 49980.27, 60028.50 and 61195.57 net incomes per hectare, respectively from BRRIdhan28, BRRIdhan29 and hybrid rice. The BCRs of the BRRIdhan28, BRRIdhan29 and hybrid rice of control respondents were 1.96, 2.12 and 1.86 , respectively while the same for the treatment respondents were $2.11,2.16$ and 2.14 , respectively. 
Table 3. Multiple regression analysis showing influence of selected socio-economic factors on profitability of rice seed production

\begin{tabular}{clccc}
\hline $\begin{array}{r}\text { Sl. } \\
\text { No. }\end{array}$ & Independent variables & $\begin{array}{c}\text { Regression } \\
\text { coefficients } \\
\text { (b values) }\end{array}$ & t values & $\begin{array}{c}\text { Level of } \\
\text { Significance } \\
\text { (p values) }\end{array}$ \\
\hline 1 & Age & -0.303 & -4.608 & $0.000^{* *}$ \\
2 & Education & 0.057 & 1.087 & 0.278 \\
3 & Family size & -0.004 & -0.058 & 0.954 \\
4 & Farm size & 0.381 & 6.858 & $0.000^{* *}$ \\
5 & Farming experience & -0.100 & -1.592 & 0.113 \\
6 & Knowledge & 0.155 & 2.682 & $0.028^{*}$ \\
7 & Attitude & 0.018 & 0.339 & 0.735 \\
8 & Training received & 0.094 & 1.726 & 0.086 \\
9 & Sources of information & 0.345 & 6.137 & $0.000^{* *}$ \\
10 & Annual income & 0.034 & 0.526 & 0.600 \\
\hline
\end{tabular}

$\mathrm{R}=0.741, \mathrm{~F}=16.72 * *, \mathrm{R}^{2}=0.549, \quad *=$ significant at $5 \%$ level, $\quad * *=$ significant at $1 \%$ level

Table 4. Stepwise regression analysis isolating the important socio-economic factors in explaining variance of profitability in rice seed production

\begin{tabular}{llccc}
\hline Steps & Independent variables & $\mathrm{R}^{2}$ & $\begin{array}{c}\mathrm{R}^{2} \\
\text { Change }\end{array}$ & $\begin{array}{c}\text { Contribution } \\
\left(\mathrm{R}^{2} \text { Change }\right. \\
\text { X 100) }\end{array}$ \\
\hline I & Contact with sources of information & 0.246 & - & $24.6 \%$ \\
II & Contact with sources of information + Farm size & 0.362 & 0.116 & $11.6 \%$ \\
III & Contact with sources of information + Farm Size + Age & 0.426 & 0.046 & $4.6 \%$ \\
IV & Contact with sources of information + Farm Size + & 0.472 & 0.046 & $4.6 \%$ \\
\hline
\end{tabular}

\subsection{Contribution of selected socio-economic factors on profitability of rice seed production}

Multiple regression analysis was done to determine the influence of various characteristics of the respondents on the dependent variable i.e. profitability of rice seed production. In the present study, regression analysis was employed to determine the influence of the independent variables on the dependent variable both individually and jointly.

Data presented in Table 3 indicate that multiple $\mathrm{R}$ and $\mathrm{R}^{2}$ values in full model regression were 0.741 and 0.549 , respectively. The corresponding F- value $\left(16.72^{* *}\right)$ was found highly significant. The above facts indicate that all the selected socio-economic factors have a joint correlation value with the profitability of rice seed production (i.e. $\mathrm{R}=0.741$ and corresponding $\mathrm{R}^{2}$ value is 0.549 ), which means that all the socio-economic factors have combinedly explained $54.9 \%$ of the total variance of profitability in rice seed production. Out of 10 socio-economic factors, age, farm size, contact with sources of information and knowledge was found significantly correlated with profitability of rice seed production. All significant variables, except age were positively related with profitability of rice seed production.

Step-wise regression analysis of all the socioeconomic factors (Table 4) revealed that the 
factor- contact with information sources $(24.6 \%)$ emerged as the single-most outstanding contributor to profitability of rice seed production followed by farm size $(11.6 \%)$, age (4.6\%) and knowledge (4.6\%). All the above socio-economic factors combinedly explained 47.2 percent of the total variance in profitability of rice seed production. Out of this 47.2 percent explained variance, contact with sources of information and farm size jointly explained 36.2 percent, signifying that these two socioeconomic factors are the most dominant variables contributing to profitability of rice seed production. Khan (2004) reported that education level and family size significantly affected the return of Boro rice.

\section{Conclusions and Recommendation}

The results of the study show that old aged farmers having primary level of education dominated in government's quality seed production project, which is not a good sign for adoption of any new practices. Moreover, age of the respondents was recognized as a significantly negative contributor in profitability of seed production. Hence, future project activities may encourage on involving younger to middle aged educated beneficiary in project activities. The average benefit cost ratio (total cost basis) was found 1.44 which is not satisfactory considering the present economic context. Contact with the sources of information emerged as the singlemost outstanding positive contributor to profitability of rice seed production followed by farm size (positive contributor), age (negative contributor) and knowledge on rice seed production (positive contributor). Contact with sources of information and farm size combinedly explained 36.2 percent of variability signifying that these two socio-economic factors are the most dominant factors contributing to profitability of rice seed production. The farmers were largely dependent on the information sources of The Department of Agricultural Extension (DAE), neighboring farmers and seed dealers regarding seed production. However, the information sources sometimes cannot provide appropriate technical support due to complexity of the system as a whole. Measures may be therefore, taken to establish better linkages among DAE, research organizations and farmers. Economic activity programmes for the farmers like introduction of Seed Village, Youth Group formation with small credit and irrigation device support for seed production, Community level seed production programme etc. may be undertaken by the GO-NGO partnerships to support the farmers for income generation from seed production and marketing activities.

\section{References}

Ali, M. Y., Waddington, S. R., Hodson, D., Timsina, J. and Dixon, J. 2008. Maizerice cropping systems in Bangladesh: Status and research opportunities. Mexico, D.F.: CIMMYT. 11-12 pp.

Anonymous. 2003. Meaning of impact http//www.thegoldenteelinks.com/default. asp.https://www.cu.edu/cuimpact2003/me asure.html

Chowdhury, A. K. M. H. U., Haque, M. E. and Hoque, M. Z. 2012. Farmers Response towards Cultivation of BRRI dhan47 in the Coastal Saline Area. International Journal of Sustainable Agricultural Technology, 8 (1): 13-18.

Huda, M. N. 2001. Why quality seed? Reality and Vision. GTZ Office Dhaka, House CWS (B) 49, Road 28, Gulshan-1, Dhaka1212, Bangladesh.

Islam, M. N. 2010. Studies on Policy Option for Quality Seed Production and Preservation of Cereal Crops at Farmer's Level for the Improvement of Food Security. A project under National Food Policy Capacity Strengthening Programme (NFPCSP), DAE, Bangladesh.

Khan, M. A. K. 2004. Productivity and Resource Use Efficiency of Boro Rice Cultivation in some Selected Haor Areas of Kishoreganj District. MS Thesis, 
Department of Agricultural Economics, Bangabandhu Sheikh Mujibur Rahman Agricultural University, Gazipur.

Kothari, C. R. 1990. Research Methodology: Methods \& Techniques (First Edition), Ansari Road, Daryaganj, New Delhi 110 002.
Rahman, F. M.M. 2011. Hybrid Rice Cultivation and Its Impacts on Social Inqueality in Some Selected Areas of Bangladesh. Ph.D. Thesis, Department of Agricultural Extension and Rural Development, Bangabandhu Sheikh Mujibur Rahman Agricultural University, Gazipur. 